\title{
CONSUMER RESPONSIVENESS TO MOBILE MARKETING
}

\author{
Kristina Heinonen and Tore Strandvik \\ Hanken Swedish School of Economics and Business Administration, Helsinki, Finland \\ kristina.heinonen@hanken.fi and tore.strandvik@hanken.fi
}

\begin{abstract}
From a marketing communication point of view, new digital marketing channels, such as Internet and mobile phones, are considered to be powerful opportunities to reach consumers by allowing interactivity and personalisation of the content and context of the message. The increased number of media has, however, led to a harder competition for consumers' attention. Given the potential of digital media it is interesting to understand how consumers are going to relate to mobile marketing efforts. The purpose of the paper was to explore consumers' responsiveness to mobile marketing communication. With mobile marketing we refer to the use of SMS and MMS as marketing media in push campaigns. It is argued in the paper that consumer responsiveness is a function of personally perceived relevance of the marketing message as well as on the disturbancelacceptance of the context of receiving the message. A relevance/disturbance framework can thus measure the effectiveness of mobile marketing communication. An empirical study was conducted in Finland, where responsiveness to mobile marketing was benchmarked against e-mail communication. Findings from this study indicated that responsiveness to mobile marketing communication varies among consumers. Compared to traditional direct mail and commercial email communication, the responsiveness to mobile marketing was considerably lower. However, even if the majority of consumers showed low responsiveness to mobile marketing there were also consumers who welcome such messages.
\end{abstract}

Keywords: Consumer responsiveness, mobile marketing communication, relevance, disturbance

\section{INTRODUCTION}

Technology developments have created new marketing communication channels or media such as email, SMS (Short Messaging Service) and MMS (Multimedia Messaging Service). These digital media are considered to potentially improve the possibilities to reach consumers by allowing personalisation of the content and context of the message (Forrester Report 2001). Simultaneously there is a potential downside to the development of new digital channels. In a Forrester report companies using SMS expressed fear for invasion of consumer privacy $(80 \%)$ and negative consumer reaction $(60 \%)$ as disadvantages of the media (Forrester Report 2001, p. 3). A crucial question is thus whether there are obstacles for the marketer to use mobile media to its potential. Are customers more reluctant to receive 
marketing information through mobile media than through traditional media or is it the other way around?

In a comprehensive survey concerning consumers' experiences of direct marketing channels in Finland it was found that consumers perceived direct marketing channels differently compared to each other. (Finnish Direct Marketing Association, 2002) The experiences of mail order, Internet and email experiences were more positive compared to other direct market channels such as telemarketing and door-to-door sales. $80 \%$ of the respondents had positive experiences of mail order, $77 \%$ had positive experiences of Internet and email as marketing channels and the corresponding number for SMS and WAP was $65 \%$. For telemarketing and door-to-door sales the number of positive consumers was down to $30 \%$ and $25 \%$ respectively. Concerning satisfaction with information received, there seemed to be differences between the channels. The study also indicated that consumers have considerable less experience of SMS messages compared to mail order, Internet and email.

When looking at marketing communication from a consumer perspective the issue of media effectiveness is challenging. The increased number of media has led to a harder competition for consumers' attention. Attention and time has increasingly become scarce resources for the consumers in the information age. It has been argued that the information age empowers consumers and creates immediate 24-hour access, which changes consumers' behaviour (Seybold 2001). Many consumers have attitudes; aspirations and purchasing patterns that are different compared to what companies have been used to. Today's consumers are claimed to be independent, individualistic, involved and informed, (Lewis and Bridger 2000) which makes it harder than ever to conduct interruption-based communication. In a permissionmarketing context it has been argued that if the consumers have agreed to pay attention it would be easier to reach them about offerings (Godin 1999).

New media in the digital economy have created potentially powerful tools for direct and interactive marketing. Traditional marketing communication strategies have been based on the interruption logic (Godin 1999) where the consumer is forced to momentarily pay attention. Permission marketing was introduced as a new managerial approach in marketing communication. It has been argued that firms benefit from getting consumers' permission to be contacted (Marinova, Murphy and Massey 2002). Permission from the consumer would resolve the difficulties to get access to the consumer. Permission is, however, not necessarily a guarantee that the consumer pays attention, it is only a door opener and gives an indication of the consumer's potential interest areas.

In traditional research concerning advertising and media effects the consumer's perspective has been largely overlooked. Traditional marketing communication planning has focused on the marketer's objectives of reaching relevant consumers (Stewart \& Pavlou 2002). An open question is, however, what reaching means when considering the empowered and active consumer. A key issue is the responsiveness of the consumer to marketing communication. Responsiveness depicts the consumer's willingness to receive and respond to marketing communication and can be viewed as a function of the content and the context of the message. Any channel can and should be evaluated according to consumer responsiveness in order to understand communication effects and effectiveness. Consumer responsiveness is potentially more effective than permission because it assumes consumer attention rather than merely permission. 


\section{Purpose of the paper}

The main purpose of the paper is to explore consumers' responsiveness to mobile marketing communication compared to email as a marketing media. With mobile marketing we refer to marketing communication where a consumer can be reached anywhere anytime but specifically in this study to SMS and MMS. From the marketer's perspective it would be crucial to know which consumers are open and responsive to such marketing communication. From an academic perspective the issue of responsiveness to a media is interesting in itself. It is assumed that the media influences the effect of the marketing communication in addition to the marketing message. We do, however, not account for the creative aspect of marketing communication, which is traditionally considered to have a significant role on the effect of the communication.

In this study we are applying a traditional communication perspective in the sense that we only explore responsiveness to marketer initiated (push) communication as a reaction to this activity. Thus, in this study we do not imply interactivity within a customer relationship or customer initiated (pull) communication.

Responsiveness to SMS, MMS and email is explored in an empirical study conducted among a convenience sample of consumers in Finland 2003. The study is based on interviews with consumers where they respond to different scenarios. An earlier similar study in Finland 2002 (Heinonen and Strandvik 2003) laid the foundation for the design of this study. That study indicated that the responsiveness framework captures differences between media as well as indicated that there are different consumer responsiveness segments.

\section{THEORETICAL FRAMEWORK}

In this paper we concentrate on modelling consumer responsiveness as a function of consumer perceived relevance of the content of the marketing communication and acceptance/disturbance of the marketing channel. Our responsivenss model can be related to traditional media performance models as it focuses on the perhaps most challenging aspect, how marketing communication is attended to and reacted on (Harvey 1997, Informed 2001).

The most influential model for comparing media is probably the ARF (Advertising Research Foundation) model first published 1961 (Harvey 1997). This model was created as a response to the need in the advertising industry to compare different advertising media (Harvey 1997). The model contains six stages or hierarchical levels of advertising effects. The original model contained the following levels; vehicle distribution, vehicle exposure, advertising exposure, advertising perception, advertising communication and sales. The first two levels indicate measures of potential spread of the media among consumers and have been the most used factors in the marketing communication industry. Advertising exposure refers to the number of consumers exposed not to the media as such but to the particular commercial or ad. The fourth level, advertising perception is the first level to include a consumer reaction, i.e. the number of consumers noticing the advertising. The next level, advertising communication, would measure how many consumers in fact receive something of the content besides only noticing the communication. These two levels have been the least studied and understood in the advertising industry, which has focused on the two first levels and the last, sales that are easier to measure. As the model is considered to be a hierarchical model there is something of 
a black box in the knowledge of consumer response. The direct marketer may record a pull or response rate in sales of, for example, $2 \%$ compared to response rate of $8 \%$ in another marketing campaign but have no information about the reason for the difference. The problem is accentuated on one hand when new media have evolved and on the other hand when customer relationships have come into focus instead of only campaign sales. Harvey (1997) argues that the advertising communication level needs more attention. In this model responsiveness would relate to the levels advertising perception and advertising communication, which have been the least studied aspects.

In a new edition of the model the Advertising Research Foundation (ARF) included new digital media and created eight hierarchical levels of media performance; vehicle distribution, vehicle exposure, advertising exposure, advertising attentiveness, advertising communication, advertising persuasion, advertising response and sales response (Informed 2001). The three first are essentially retained from the original model as well as the last level. In this model our responsiveness framework links to advertising attentiveness, communication and persuasion.

According to the descriptions of the new model (Informed 2001) advertising attentiveness is considered to be a measure of the degree to which those exposed to the advertising are focused on it. Advertising communication refers to information retained by the consumer after exposure to the message. Advertising persuasion measures shift in attitudes and/or intentions produced by the communication and advertising response is other consumer response than purchasing. This would for example, include click-through, lead generation, mail response and coupon redemption.

Our responsiveness conceptualisation closely relates to the attentiveness level but carries over to the communication and persuasion levels in the sense that we assume that they are closely related. As the model is considered to be a hierarchical model where the consumer climbs the stairs, the reason for low advertising and sales response rates are in the earlier stages of the model. We also make the assumption that there are differences in responsiveness among consumers concerning different media as well as concerning different products. The responsiveness may be higher for some media for some consumers because they are more familiar with the media and it suits their purposes. In this respect also certain products or offerings may receive higher responsiveness than other.

In the next section we are developing and discussing the foundation for our theoretical framework.

\section{Consumer responsiveness}

Consumer responsiveness can be considered to be based on a function of content relevance and channel acceptance/disturbance (Heinonen \& Strandvik 2003). Relevance relates to the content of the communication, what kind of value the consumer receives from the marketing communication. Channel acceptance/disturbance depicts the context of the communication. This means that an extended definition of the channel is used and it includes how, when and where the consumer receives the communication. These aspects are derived from service quality models (Grönroos 1982) where perceived service quality traditionally has been modelled as technical (what the consumer receives) and functional quality (in which way the consumer receives the technical quality). Following the line of Balasubramanian et al. (2002) 
it would also seem reasonable to expect that time- and location-specific elements that create the context when and where the service delivery occurs may impact perceived service quality.

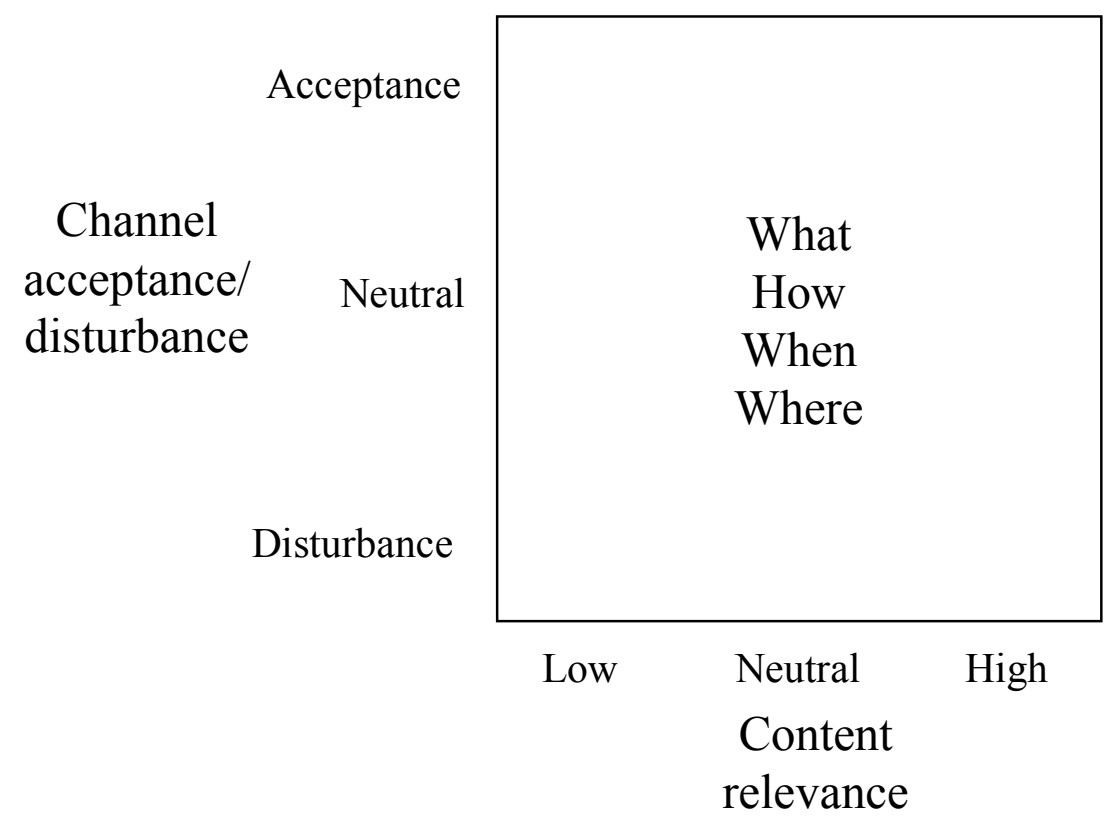

Figure 1: Factors influencing the consumer's responsiveness to marketing communication

The probability of obtaining attention from the consumer should increase with higher content relevance and channel acceptance. The upper right hand corner in the figure is a situation where content is perceived relevant and the channel is perceived as accepted because of few contextual disturbances. This is actually the optimal case to get high responsiveness. In contrast, the lower left hand corner depicts situations where the channel is highly disturbing and the content is of low interest. In these cases consumers may be less responsive to marketing communication.

With a value creation perspective (Heinonen 2003) the upper right hand corner represents situations of channel acceptance and high relevance where the marketing communication in itself creates value to the consumer and is a part of the company's total offering. Situations in the opposite corner representing high disturbance and low relevance depict negative value creation. This view where the marketing communication either creates of destroys value for the consumer contrasts the traditional media effect paradigm where the marketer's interests are in focus. Following Heinonen (2003) it can be argued that value is created on four basic dimensions: the technical, functional, spatial and temporal dimensions corresponding to whatvalue, how-value, where-value and when-value.

\section{Acceptance/disturbance}

Studies in advertising have been focused on understanding consumers' responses to marketing communication. The concept of intrusiveness has been suggested to influence the consumer's perceptions marketing communication. Intrusiveness may be useful to describe how negative feelings arise from advertisements ( $\mathrm{Li}$ et al. 2002). It is related to feelings of irritation, leading to avoidance behaviour. The intrusiveness scale is based on measuring 
whether an ad is distracting, disturbing, forced, interfering, intrusive, invasive or obtrusive. The personal nature of direct marketing communication may even step over the line of discretion and invade consumers' privacy. For example, unsolicited email and spam mail are considered an invasion of privacy and have actually become a serious problem for many consumers (Windham and Orton 2000).

The channel influences consumer responsiveness to marketing communication by being perceived as either disturbing or acceptable. If the consumer considers marketing communication via a channel as disturbing it may negatively affect the attention to and perception of the message. In contrast, the channel may also enhance the acceptance of the marketing communication if it is perceived as appropriate for the specific marketing communication. Also, some consumers may perceive the channels as neutral, i.e. it is neither disturbing nor accepted.

In this respect, the disturbance effect of marketing messages is of interest because the new interactive media allows more direct contact with the consumer. Consumer responsiveness and attention to marketing communication is influenced by the situation in which the consumer receives the marketing messages. Because of the interactive and personal nature of digital channels the consumer can be in various situations when receiving the marketing message. Li et al. (2002) argued that interruptions may be extremely intrusive when they are unexpected. For example, marketing messages to the mobile phone can reach consumers everywhere when shopping, at meetings, at dates etc. The time and even the place can be more or less appropriate for the consumer to acknowledge and take interest in the marketing message. Supposedly, this reduces consumers' attention to the marketing message and it may even be perceived as disturbing.

In addition to the effect of the situation, the level of disturbance varies for different channels. Some consumers perceive traditional direct mail as disturbing and put a sign on the mailbox to avoid getting advertisements. Others dislike direct telephone selling because of the personal and direct nature of the channel. On the contrary, consumers that see the direct marketing communication as a welcomed way to receive information about offers and new product launches would probably be most appreciative of SMS offers to the mobile phone because they can be highly situation-specific.

\section{Relevance}

Another aspect that influences the consumer's responsiveness to marketing communication is the interest in and relevance of the marketing message. Li et al. (2002) found that the intrusiveness of advertisements may be moderated by the utility that consumers derive from the content. It may be difficult to create relevant marketing communication content, as the relevance is most likely consumer specific. In other words something that is relevant for one consumer is probably less relevant for another consumer. For example, one consumer is interested in golf, another consumer is interested in motor sports or gardening and a golf brochure probably draws the attention of the golf enthusiast and leaves the motor sport enthusiast indifferent. 
High relevance may have two different roots. High commitment to a certain brand or service provider may make the consumer more responsive to marketing communication concerning that specific brand or service firm. Similarly, high involvement in a product category or activity may lead to higher consumer perceived relevance for corresponding marketing communication. These roots of perceived relevance might be called focused relevance created by commitment and information relevance generated through involvement.

\section{EMPIRICAL STUDY}

An initial empirical study was conducted in Finland in February 2002 to compare consumer responsiveness to marketing communication concerning 15 services and products received by direct mail, email, SMS and in different situations (Heinonen \& Strandvik 2003). The size of the convenience sample was 66 respondents but each respondent assessed 1-4 offerings in 2-3 situations resulting in a total sample size of 1179.

This first study showed that the responsiveness to marketing communication is lower for digital channels (email and SMS) compared to traditional direct mail. Both email and SMS communication had a high percentage of negative responsiveness, however, the percentage of negative responsiveness to SMS communication was the highest. These findings indicated that consumers are the least responsive to the mobile channel, compared to email and direct mail. Considering that there were different perceptions of SMS and email as marketing communication channels it seemed appropriate to compare the digital channels to each other. Consequently, another study was designed to contrast consumer responsiveness to marketing communication in the mobile channel to email. It was thus decided to compare responsiveness to SMS, MMS and email using the same theoretical framework as in the first study.

The main empirical study was conducted in Finland in March 2003. Data was collected by interviewing consumers on how they perceive marketing communication concerning six hypothetical scenarios of two offerings received by SMS, MMS and email. The scenarios were designed so that they assumed that the respondent had given permission for the marketing activity.

The size of the convenience sample that assessed the relevance and disturbance of marketing communication was 146, but each respondent assessed six scenarios based on a consumer good and a capital good in each of the three channels.

The disturbance and relevance was measured on a three-point scale ranging from positive, through neutral to negative perceptions. For disturbance the scale points were in a free translation from Swedish defined as "I would appreciate to get the advertisement via this channel", "I am indifferent concerning getting advertisement via this channel" and "I perceive it as disturbing to get the advertisement via this channel". Relevance was defined as "This kind of advertisement seems relevant and interests me", "I perceive this kind of advertisement as neither positive nor negative" and "This kind of advertisement does not seem relevant and does not interest me". All interviews were audio taped and transcribed and the relevance/disturbance perceptions were coded for each respondent. 


\section{Findings}

For each channel the respondents' responses as an average of all offerings (scenarios) in different media are depicted in Figure 2-5 in percentages of all responses. Figure 2 illustrates the responsiveness to marketing communication on an aggregated level as an average of all three media. $11 \%$ of the respondents perceived the marketing communication as highly relevant and accepted, while $37 \%$ perceived the marketing communication in digital channels as highly disturbing and with low level of relevance. A total of $21 \%$ in the middle of the figure were neutral to the content and channel.

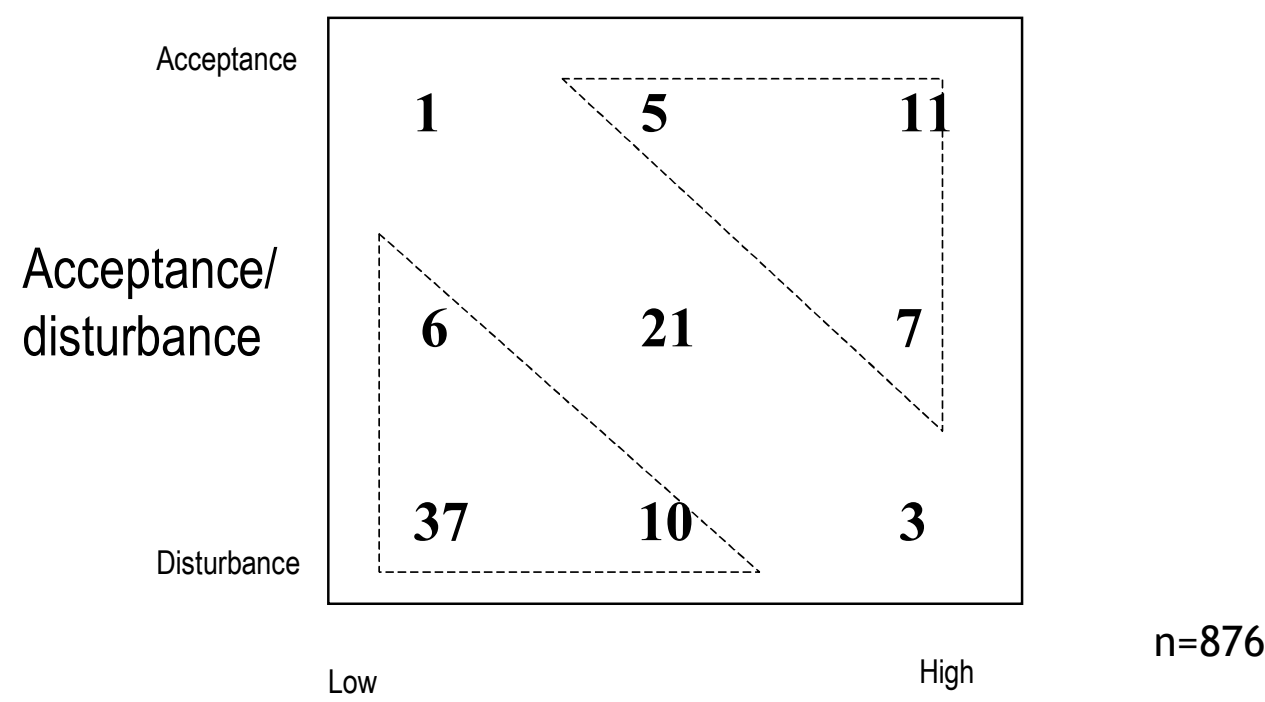

\section{Relevance}

Figure 2: Consumer responsiveness to marketing communication in digital channels

There are differences between SMS, MMS and email when looking at the consumer responsiveness separately for each channel. Figure 3 shows the consumer responsiveness to email and it indicates a higher level of responsiveness compared to the overall aggregated figures. $23 \%$ of all the respondents perceived marketing communication via email as disturbing and not relevant, while $15 \%$ were at the other extreme perceiving the content as relevant and accepted the channel. $28 \%$ of the respondents were neutral to the content and channel. Interestingly, there were also respondents that perceived marketing communication as either highly relevant but disturbing $(3 \%)$ or accepted but with low relevance $(1 \%)$. 


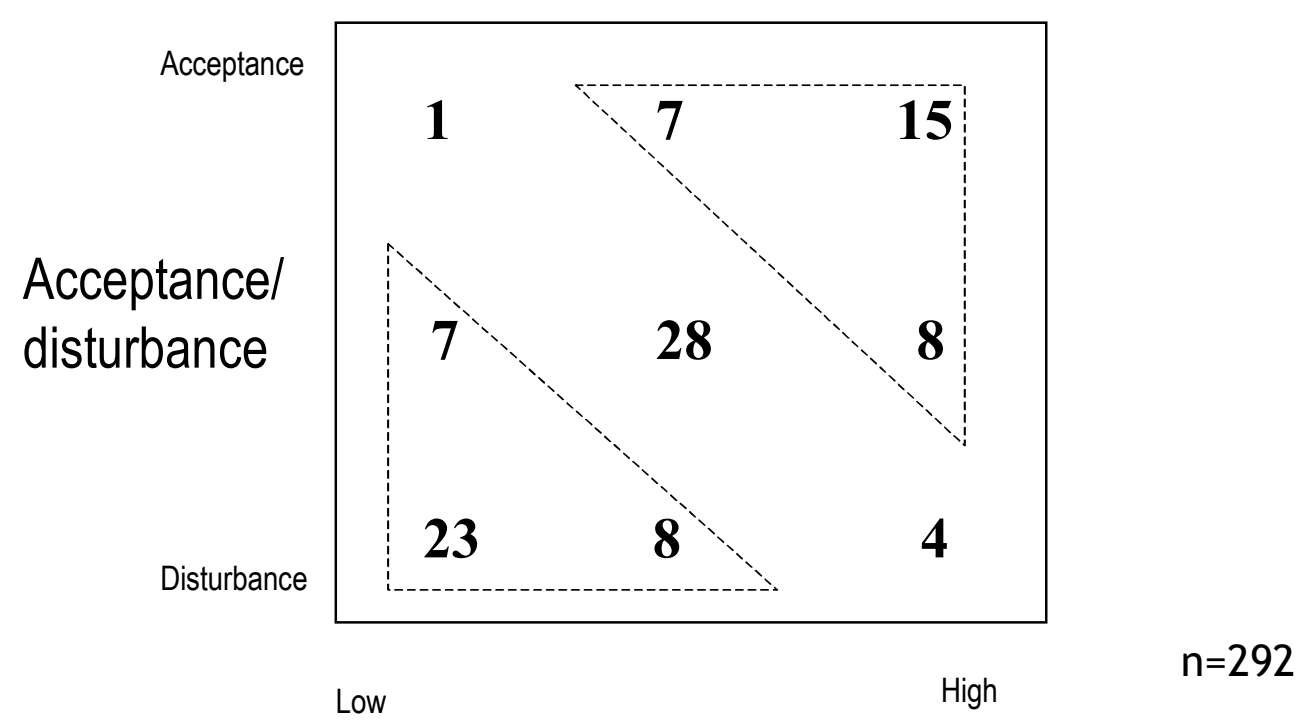

\section{Relevance}

Figure 3: Consumer responsiveness to email

Figure 4 represents the responsiveness to SMS on an aggregated level. A total of $48 \%$ of the respondents perceived SMS as disturbing and marketing communication as irrelevant.

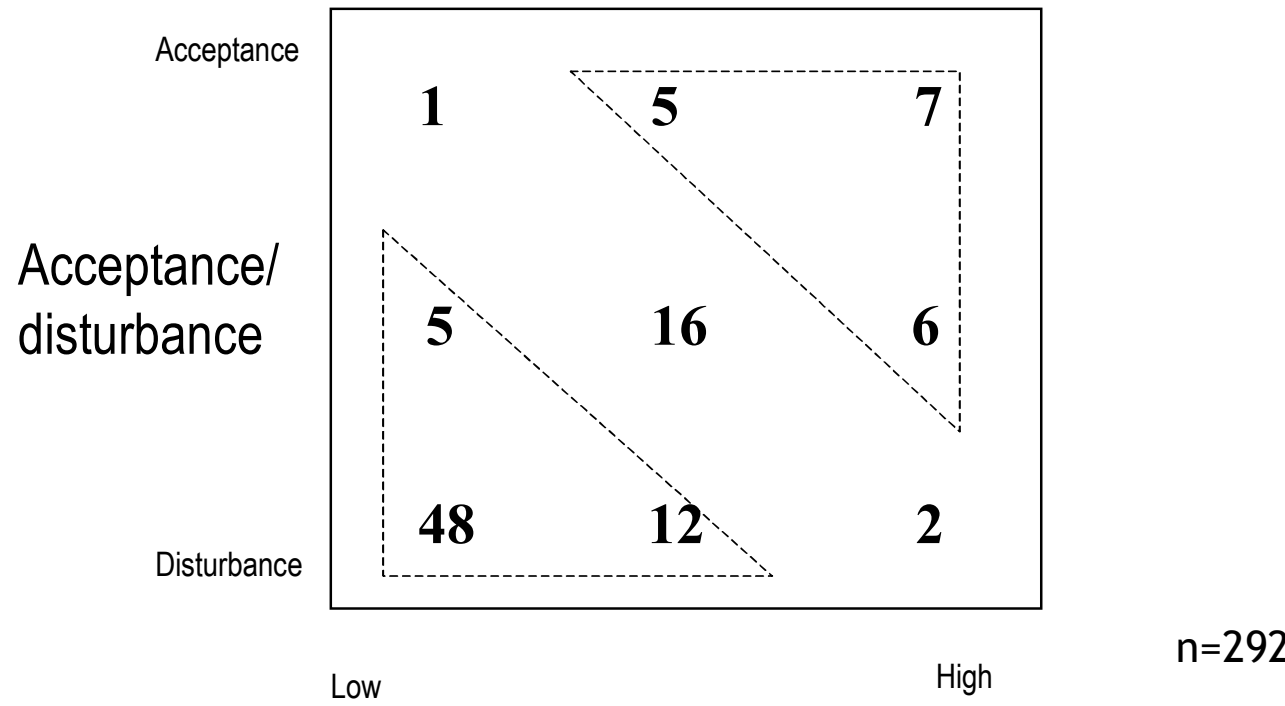

\section{Relevance}

Figure 4: Consumer responsiveness to SMS

Only $7 \%$ of the respondents felt that the marketing communication is relevant and SMS an accepted channel. $16 \%$ of the respondents were in between and perceived the SMS as neutral.

The responsiveness to MMS is depicted in figure 5, showing that $42 \%$ of the respondents feel low relevance of the marketing communication and high disturbance of MMS as channel. However, it seems that the responsiveness may be somewhat higher than for SMS, as the percentage of neutral respondents was 18 , and also the percentages of the two extreme points 
(high relevance and acceptance as well as low relevance and disturbance) was higher (10\% compared to $7 \%$ ) respectively lower ( $42 \%$ compared to $48 \%$ ).

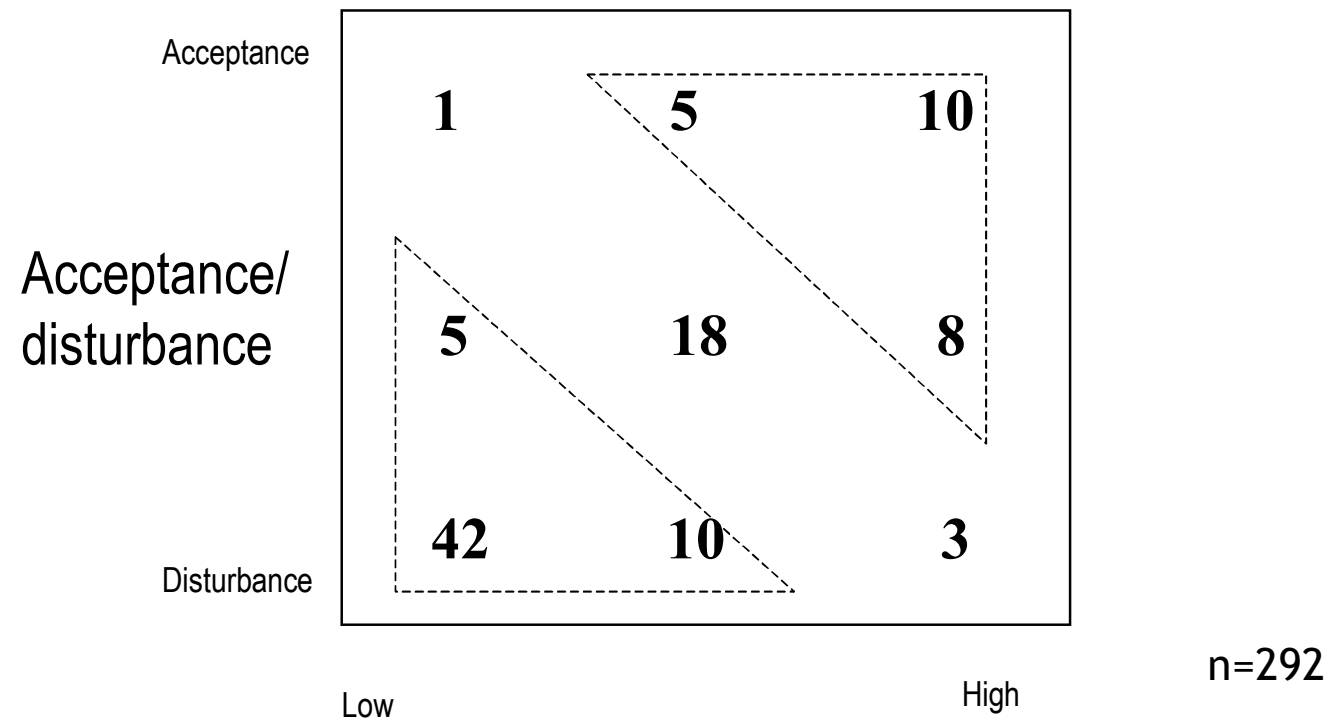

\section{Relevance}

Figure 5: Consumer responsiveness to MMS

To effectively explore differences in consumer responsiveness it is helpful to create responsiveness groups of each channel. By combining the three lower left hand corner responses we get a total figure of consumers that are critical towards marketing communication based on high disturbance and/or low relevance. This triangle is labelled negative responsiveness. Correspondingly combining the three upper right hand corner responses (the upper right hand triangle) we get a total figure for consumers with a positive view on marketing communication, i.e. positive responsiveness. The remaining diagonal elements represent a perception of indifference or balance between disturbance and relevance. We choose to label this diagonal indifference. When comparing media this simplified perspective as well as the full distribution of the model can be used. Thus we can conclude, that negative responsiveness for SMS, MMS, and email are $65 \%, 57 \%$ and $38 \%$ respectively. This can be compared with a figure of 41 for traditional direct mail from the earlier study (Heinonen and Strandvik 2003). Positive responsiveness is respectively, $18 \%$, $23 \%, 30 \%$ and $27 \%$.

The negative, indifferent and positive responsiveness groups allow for comparison of the responsiveness distributions in different age groups.

Table 1: Consumer responsiveness by age groups

\begin{tabular}{llll}
\hline & Negative & Indifferent & Positive \\
\hline-20 & 55 & 24 & 21 \\
$21-30$ & 48 & 25 & 27 \\
$31-$ & 70 & 22 & 8 \\
\hline
\end{tabular}


Looking at the responsiveness in different age groups for all the channels shows that group 2, respondents in ages ranging form 21 to 30, had the lowest level of negative responsiveness $(48 \%)$. In contrast, group 3 with respondents over 31 years of age had the lowest level of positive responsiveness $(8 \%)$ and also the highest level of negative responsiveness, indicating that this group was the most negative towards marketing communication in digital channels. It is interesting to note that the youngest group with respondents under 20 years were less responsive to marketing communication in digital channels than respondents between 21 and 30 years. When separating the responsiveness distributions for each channel by age groups then differences can be found. The study showed that the age group with respondents in ages 21-30 was more responsive to email than the youngest and the oldest age groups, see table 2 . In this age group, $66 \%$ were either indifferent or positive towards email communication compared to $56 \%$ or $50 \%$ for the youngest and oldest age groups respectively. The number of negative responsiveness was also the smallest for respondents between 21 and 30 . Respondents over 31 were the most negative towards email communication with $50 \%$ of the respondents in the negative responsiveness group.

Table 2: Consumer responsiveness to email by age groups

\begin{tabular}{llll}
\hline Email & Negative & Indifferent & Positive \\
\hline-20 & 44 & 31 & 25 \\
$21-30$ & 34 & 35 & 31 \\
$31-$ & 50 & 28 & 22 \\
\hline
\end{tabular}

Table 3 depicts the responsiveness to SMS in the three age groups. The number of negative respondents is higher than for email in all age groups. The oldest age group was significantly higher than for the two other age groups $(83 \%)$. In line with the responsiveness to email communication, respondents between 21 and 30 were the most positive towards SMS communication, with $40 \%$ of the respondents being either positive or indifferent. However, the number of indifferent respondents was higher in the youngest age group (25\%) compared to $18 \%$ for respondents in ages $21-30$ and $15 \%$ for respondents above 31 . In fact, the number of indifferent respondents in the middle age group was only slightly higher than for the oldest age group, $18 \%$ compared to $15 \%$.

Table 3: Consumer responsiveness to SMS by age groups

\begin{tabular}{llll}
\hline SMS & Negative & Indifferent & Positive \\
\hline-20 & 63 & 25 & 12 \\
$21-30$ & 60 & 18 & 22 \\
$31-$ & 83 & 15 & 2 \\
\hline
\end{tabular}

Responsiveness to MMS is illustrated in table 4. Again, the middle age group is more positive towards the channel, with $49 \%$ of the respondents included in either the positive of indifferent responsiveness groups. Interestingly, although the oldest age group was considerably more negative towards MMS communication compared to the two other groups, the rest of the respondents fell into the indifferent responsiveness group $(22 \%)$. This indicates that the respondents in this age group may be sensitive towards communication in this channel. In the youngest age group, in contrast, there were more positive than indifferent respondents. 
Table 4: Consumer responsiveness to MMS by age groups

\begin{tabular}{llll}
\hline MMS & Negative & Indifferent & Positive \\
\hline-20 & 59 & 16 & 25 \\
$21-30$ & 51 & 22 & 27 \\
$31-$ & 78 & 22 & 0 \\
\hline
\end{tabular}

Figures 3, 4 and 5 show that although there are different opinions about the channels, there is also a consistent overall tendency indicating lower responsiveness to mobile channels compared to email. Comparing the structure of the total responses for email, SMS- and MMSmessages we can conclude that the fraction of negative respondents increases and the fraction of positive respondents decreases for the mobile channels. Interestingly, the positive responsiveness to MMS is larger than the responsiveness to SMS. Also, the middle age group is more positive towards all the channels compared to the other two age groups.

Responsiveness to different offerings can also be separated into negative, indifferent and positive responsiveness groups:

Table 5: Consumer responsiveness to different offerings

\begin{tabular}{llll}
\hline & Negative & Indifferent & Positive \\
\hline CapG Clothes & 35 & 28 & 37 \\
ConG CD & 35 & 35 & 30 \\
CongG Pizza\&Hamburger & 41 & 37 & 22 \\
ConG Cosmetics & 45 & 23 & 32 \\
CapG Garden products & 55 & 20 & 25 \\
CapG Home electronics & 63 & 15 & 22 \\
CapG Magazines & 63 & 33 & 3 \\
CapG Water \& Soft drinks & 64 & 21 & 16 \\
CapG Furniture & 65 & 22 & 13 \\
ConG Coffee \& milkproducts & 66 & 17 & 17 \\
\hline
\end{tabular}

Table 5 indicates the responsiveness to different consumer and capital goods showing quite a few differences between the responsiveness distributions. The table shows the offerings in decreasing levels of responsiveness. The negative responsiveness ranged from $35 \%$ to $66 \%$ while positive responsiveness varied between $15 \%$ and $37 \%$. The positive responsiveness group ranged between $37 \%$ and $3 \%$ indicating a larger difference between the perceptions compared to the other responsiveness groups.

The offerings that received highest positive responsiveness were clothes and CD $(37 \%$ and $30 \%$, respectively), which are typical direct marketing offerings. The responsiveness to these offerings was also equally distributed in the three responsiveness groups (ranging from 28$37 \%$ ), indicating a rather balanced consumer perspective on marketing efforts. Responsiveness to coffee and milkproducts was the lowest of all offerings, with $66 \%$ of the respondents falling into the negative responsiveness group. The earlier study showed that offerings that are traditionally included in direct marketing campaigns such as travel and hotel services, music, pizza and books received relatively high positive and neutral responsiveness percentages (Heinonen \& Strandvik 2003). Still about half of the respondents were not responsive to marketing communication related to these offerings, and the rest were more or less equally distributed in the neutral and positive responsiveness groups. 
The positive responsiveness to cosmetics in this study was the second highest $(32 \%)$, however, the number of negative responsiveness is $45 \%$. This indicates that respondents felt that this product group was either relevant or not relevant. It cannot directly be explained with gender differences because the number of respondents in the study was exactly $50 \%$ male and $50 \%$ female. In comparison, in the earlier study the marketing of cosmetics was perceived as disturbing and not relevant by $80 \%$ of the respondents (Heinonen \& Strandvik 2003).

Interestingly, the responsiveness distribution of magazines was different from the rest. Only $3 \%$ of the respondents were positively responsive to magazines, although $33 \%$ were indifferent. This is consistent with findings from earlier studies, where consumers are not responsive to the marketing of magazines (Heinonen \& Strandvik 2003). The reason for this may be related to negative perceptions of telephone sale campaigns of magazines (Finnish Direct Marketing Association 2002).

\section{DISCUSSION}

This paper focused on consumer responsiveness to mobile media by studying the channel in relation to the message and comparing it to other media. Three media were studied: SMS, MMS and email. One main implication of the study is the influence of the media in marketing communication as the channel affects consumer responsiveness to marketing communication. In other words, the message content is not the only factor in effective marketing communication.

The findings indicated that the responsiveness was lower in the mobile channels than for commercial email communication. One reason for this may be that consumers have only limited experience of marketing communication to digital channels, especially concerning commercial SMS-and MMS-messages. However, SMS communication was considered the most disturbing channel. Marketing communication as MMS was interestingly enough perceived as more appropriate than SMS communication. However, there were still more negatively responsive respondents to MMS compared to email communication. One explanation for high digital channel disturbance may be that consumers are not able to notice that the communication is commercial until opened. Traditional direct mail is in this respect more obvious as it is visually apparent that it contains other that personal messages.

This study, however, showed diverging opinions among consumers. Some consumers welcomed digital marketing communication, while others did not. By and large, there were three groups of responsiveness; those consumers that are not responsive, those that are indifferent and those that are responsive to marketing communication. This is interesting considering that consumers were assumed to have given their permission for the marketing activity. It should have resulted in higher responsiveness levels. And the responsiveness groups were applicable for all three channels as well as the offerings. This means that both the content of the marketing communication as well as the channel influence perceptions about the marketing campaign.

Content relevance and channel acceptance are not directly related to high consumer responsiveness. Content relevance in itself did not necessarily mean high responsiveness as 
the channel may have simultaneously been perceived as disturbing. In contrast, low relevance may also involve some positive responsiveness if the channel for the marketing activity was perceived as accepted.

The responsiveness was different for the age groups. Respondents in ages 21 to 30 were the most positive towards marketing efforts for all the channels. Interestingly, the youngest age grouping ages below 20 was less responsive to marketing communication in all the channels compared to the middle age group of respondents in age 21-30. Respondents above 31 years were the least responsive to marketing communication in the digital channels. These findings are consistent with the previous study that showed consistent lower level in responsiveness to digital channels compared to traditional direct mail (Heinonen \& Strandvik 2003). It showed that respondents in ages 13 to 20 did not seem to differentiate between marketing communication in traditional and digital media. The number of indifferent young respondents was largest in all channels and the percentage of negative responsiveness does not increase as much as the other groups. On the other hand, the adult groups of respondents above 21 were considerably more negative to marketing communication in digital channels.

Marketer's benefit from the ability to personalise communication in digital channels; $66 \%$ of marketers have noted that the main advantage of mobile marketing is its one-to-one communication ability (Forrester Report 2001). However, marketing communication in mobile channels may be challenging because of the personal nature of the mobile channel. From a consumer perspective, the more personal the channel is potentially the more disturbance and less relevance it may create. Consumers benchmark commercial mobile messages to private messages that obviously are perceived as more relevant and less disturbing than commercial messages.

In line with Heinonen \& Strandvik (2003) this study showed that mobile channels are perceived to be more personal than traditional and email channels. This creates high expectations for the relevance of marketing communication messages. Consumers expect messages to be personal and of high interest and this makes the disappointment greater when they get undesired messages. At the same time, $45 \%$ of marketers note another disadvantage of mobile marketing the messages limits set for SMS (Forrester Report 2001), which makes it difficult to create relevant content. Also the perceived channel disturbance is affected by the personal nature of the mobile channel. The findings from this study indicated that the perceived disturbance is high, which supports the marketers' fears of invading consumers' privacy noted in the Forrester research report (2001).

Taking a managerial perspective, the findings represent a new view on marketing communication strategy and effectiveness measurement. A firm's customers may be divided into a portfolio of different responsiveness groups. By looking at consumer responsiveness as a function of disturbance and relevance it is possible to see four different situations for increasing the likelihood of getting the consumers' attention. 


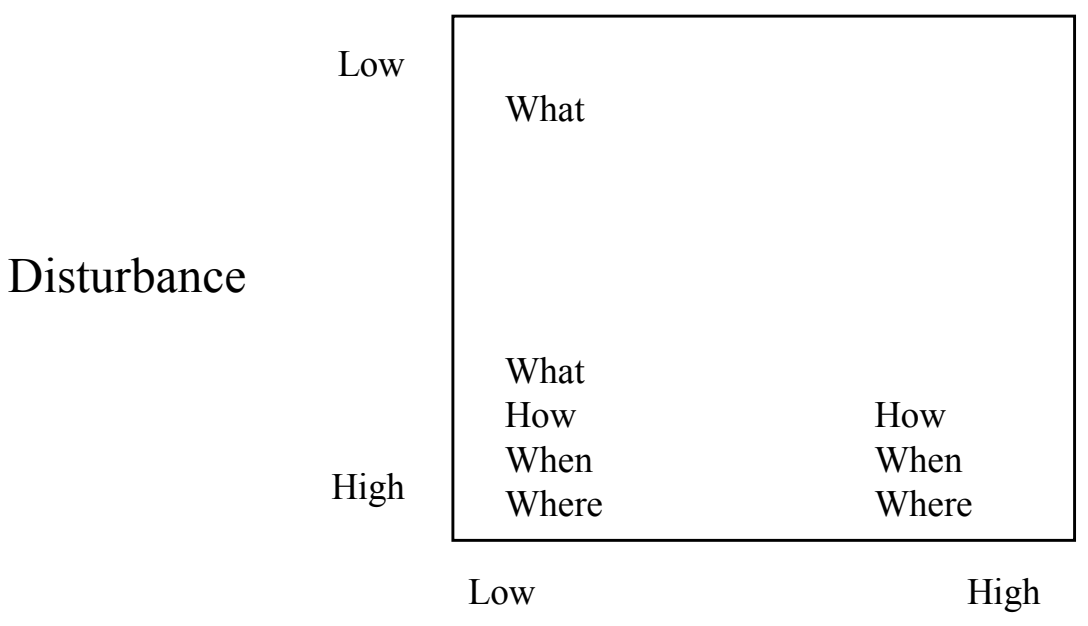

\section{Relevance}

Figure 5: Communication strategies based on customer responsiveness

In the situation where disturbance is high while relevance is low it is necessary to focus on both the context and the content of the marketing communication. In other words, the marketer must improve the value consumers receive from the message, as well as how, when and where the marketing communication is delivered to the consumer. Important to discover is who perceives the communication in this way and why.

On the other hand, in situations where the disturbance is low, but the relevance is low, the context of the marketing message seem to be satisfactory to the consumer. This means that attention can be placed on making the content more appealing, i.e. working on finding relevant offerings.

In contrast, where the relevance is high, and disturbance is high, the content seem to be valuable to the consumer. In these cases it is necessary to focus on providing the marketing communication is such situations and ways that make it even more appealing. How, when and where grow in importance.

Lastly, even in cases where disturbance is low and relevance is high it is equally crucial to recognise the importance of the content as well as the context of the marketing communication. The upper right corner of the disturbance/relevance model indicates that the consumer is currently satisfied with what the marketing communication provides as well as how, when and where it is delivered. But, considering the dynamism in consumer behaviour it is essential not to forget that the situation may change.

The paper contributes to marketing communication research by introducing the relevance/disturbance conceptualisation, with an emphasis on the active role of an empowered consumer. This conceptualisation used in this exploratory study clearly points to the need for companies to measure the responsiveness of their consumers in order to understand the effectiveness of their marketing communication in different traditional and new communication channels. 
This paper has studied consumer responsiveness to mobile marketing communication in hypothetical push campaigns. Further research needs to explore consumer responsiveness to existing mobile marketing campaigns. Also, it is interesting to study the responsiveness in other types of marketing campaigns. It has been argued that pull campaigns such as one-off pull and continued dialogue are in fact more effective (Forrester report 2001) because they potentially activate the consumer. Hence, future research needs to explore how this kind of interactive communication affects consumer responsiveness.

\section{REFERENCES}

Balasubramanian, Robert A. Peterson and Sirkka L. Järvenpää (2002). Exploring the Implications of M-Commerce for Markets and Marketing. Journal of the Academy of Marketing Science. Vol. 30 No. 4, 348-361.

Finnish Direct Marketing Association (2002): Suorat ostokanavat 2001. Tutkimus suomalaisten kuluttajien ostoista ja mielipiteistä suoramarkkinoinnin eri kanavista vuonna 2001. Helsinki: Suomen Suoramarkkinointiliitto, (Direct Marketing Channels 2001, Finnish Direct Marketing Association).

Forrester Report (2001): Lussanet et al. The Marketer's Guide to SMS, Forrester Research Inc., European Research Center, Amsterdam.

Godin, Seth (1999). Permission marketing: Turning strangers into friends, and friends into customers. New York: Simon \& Schuster.

Harvey, Bill (1997). The Expanded ARF Model: Bridge to the Accountable Advertising Future. Journal of Advertising Research. March-April, 11-20.

Heinonen, Kristina (2003). Reconceptualising customer perceived value: The value of time and location. Paper to be presented at AMA Servsig Conference. Reims, France. June, 12-14 2003.

Heinonen, Kristina \& Strandvik, Tore (2003): Consumer responsiveness to marketing communication in digital channels, FeBR2002 Frontiers of e-Business Research 2002, ed. M. Hannula, A-M. Järvelin \& M. Seppä, pp. 137-152, Tampere University of Technology and University of Tampere

Informed (2001). The "New" ARF Model. Vol. 4, No. 3, June 2001. The Advertising Research Foundation.

Li, Hairong, Steven M. Edwards and Joo-Hyun Lee 2002. Measuring the Intrusiveness of Advertisements: Scale Development and Validation. Journal of Advertising, Vol. XXXI, No. $2,37-47$.

Marinova, Murphy and Massey (2002). Permission email marketing as a means of targeted promotion, Cornell Hotel and Restaurant Administration Quarterly. February. 61-69. 
Merisavo, Marko, Jari Vesanen and Mika Raulas (2002). Suomalaisten asiantuntijoiden kokemukset ja näkemykset digitaalisten kanavien käytöstä markkinoinnissa (Finnish experts' experience and perceptions about the use of digital channels in marketing), Center of Direct Marketing Excellence, LTT Research Ltd, Institute of Electronic Commerce

Seybold, Patricia (2001). The customer revolution: How to thrive when your customers are in control. London: Random House Business Books.

Stewart, D. and Pavlou, P. 2002. From Consumer Response to Active Consumer: Measuring the Effectiveness of Interactive Media. Journal of the Academy of Marketing Science. Vol. 30. No.4., 376-396.

Windham, Laurie and Ken Orton (2002). The soul of the new consumer: The attitudes, behavior, and preferences of e-customers, Allworth Press. 